Research Paper

\title{
Significance of PD-L1 Expression in Tongue Cancer Development
}

\author{
Saori Yoshida1,2, Hitoshi Nagatsuka2 , Keisuke Nakano², Yasunao Kogashiwa3, Yasuhiro Ebihara3 , \\ Mitsutake Yano $^{1}$, Masanori Yasuda ${ }^{\circledR}$ \\ 1. Department of Pathology, Saitama Medical University International Medical Center, Saitama, Japan \\ 2. Oral Pathology and Medicine, Graduate School of Medicine Dentistry and Pharmaceutical Sciences, Okayama University, Okayama, Japan \\ 3. Department of Head and Neck Oncology/Ear, Nose and Throat, Saitama Medical University International Medical Center, Saitama, Japan \\ $\triangle$ Corresponding author: Masanori Yasuda, MD, PhD, Department of Pathology, Saitama Medical University International Medical Center, 1397-1 Yamane, \\ Hidaka, Saitama, 350-1298 Japan. Tel: +81-42-984-6090; Fax: +81-42-984-6090; E-mail: m_yasuda@saitama-med.ac.jp \\ (C) Ivyspring International Publisher. This is an open access article distributed under the terms of the Creative Commons Attribution (CC BY-NC) license \\ (https://creativecommons.org/licenses/by-nc/4.0/). See http://ivyspring.com/terms for full terms and conditions.
}

Received: 2018.06.13; Accepted: 2018.09.14; Published: 2018.11.22

\begin{abstract}
Aims: Immunohistochemistry of PD-LI has been recently established as a surrogate method to predict if immunotherapy targeting PD-L1/PD-1 has a significant effect on suppression of cancers such as lung non-small cell carcinoma, melanoma, and renal cell carcinoma. Here we performed immunohistochemistry for PD-Ll expression in squamous cell carcinoma (SCC) of the tongue to investigate the potential correlation between PD-LI expression and clinicopathological factors and whether PD-L1 expression would be associated with prognosis.

Methods: Tissue microarray cores of paraffin-embedded blocks from 135 cases with surgically resected tongue SCC were immunohistochemically analysed for PD-L1 expression.

Results: We observed a positive correlation between PD-LI expression and tongue SCC PTI and PT2 tumours, but a negative correlation with pT2, pT3 and pT4 tumours. We also observed a positive correlation with lymph node metastasis. However, no positive correlation was demonstrated between PD-LI expression and overall survival.

Conclusions: PD-L1 tends to be overexpressed at the early stage of tongue SCC, showing a close correlation with initial development of tongue. However, PD-LI expression may not affect prognosis.
\end{abstract}

Key words: PD-L1, immunohistochemistry, oral pathology, squamous cell carcinoma

\section{Introduction}

PD-L1 is a protein expressed on the surface of cancer cells that suppresses the activity of T-cells by binding to PD-1 possessed by T-cells. The subsequent suppression of immune function by PD-L1 binding would lead to promotion of tumour growth and metastasis. Treatment using anti-PD-L1 antibody results in inhibited binding of PD-L1/PD-1 and prevents immune evasion, allowing the immune system to attack cancer cells.[1-3] In 2014, the cancer immunotherapy drug Opdivo (nivolumab), a PD-L1 inhibitor, was approved for the first time in Japan for malignant melanoma and non-small cell lung cancer. However, some reports showed that cancers expressing PD-L1 had a poorer prognosis than cancers without PD-L1 expression,[4-7] while other reports showed opposite results.[8-11] The precise mechanism of immune evasion of cancer by PD-L1/PD-1 binding remains to be clarified.

Immunohistochemistry is commonly used to investigate PD-L1 expression to select cases that are appropriate for immunotherapy using nivolumab, when the anti-PD-1 antibody of 28-8 pharmDx (Dako) is recommended. Adaptation of Keytruda is evaluated immunohistochemically using the antibody 22C3 pharmDx (Dako) as a companion diagnostic agent, and the evaluation criteria are based on TPS (Tumour 
Proportion Score). For non-small cell lung cancer, the indication of primary treatment is TPS $>50 \%$, and that of secondary treatment is TPS $>1 \%$.

Therapy using anti-PD-1 or anti-PD-L1 antibody is being actively carried out in various cancers, including oral cancer. In 2017, nivolumab was approved for head and neck cancer cases with recurence or distant metastases. A correlation between the prognosis of oral cancer and PD-L1 expression has been reported.[12, 13] However, no report has confirmed the association of PD-L1 expression with clinicopathological factors, and whether PD-L1 expression is correlated with the biological behaviour or prognosis in oral cancer is unclear.

Based on these findings, here we investigated PD-L1 expression in squamous cell carcinoma (SCC) of the tongue and examined potential correlations with clinicopathological factors.

\section{Materials and Methods}

\section{Patients}

One hundred thirty-five cases with tongue SCC that were surgically resected at Saitama Medical University International Medical Center from January 2007 to September 2016 were recruited. No neoadjuvant chemotherapy was performed in the included cases. The study was approved by the institutional review board following the ethical standards of the responsible committee on human experimentation and of the Helsinki Declaration of 1975 as revised in 1983. The clinicopathological stage was determined according to the UICC $7^{\text {th }}$ edition.

\section{Immunohistochemical study}

Tissue microarray (TMA) cores of cylindrical shape with a diameter of $3 \mathrm{~mm}$ were prepared from routinely processed paraffin-embedded tissue blocks of surgically resected materials. Twenty-two cases had only a superficial core and 113 cases had both superficial and deep cores. These cores were aligned and re-embedded to produce the new blocks. The samples were run through the automated system by Dako Autostainer Link 48 (Agilent Technologies, CA, USA) according to the manufacturer's protocol. We performed staining using the PD-L1 primary antibody 28-8 (dilution 1:400, Abcam). Expression of PD-L1 was evaluated semi-quantitatively according to the degree of positive staining. PD-L1 was considered positive when 28-8 positive tumour cells accounted for $50-100 \%$ of all tumour cells. When $28-8$ positive tumour cells accounted for $0-49 \%$, PD-L1 was considered negative. [14-16]

In addition, only when the tumour cells were 28-8 positive was validated, and positive images of other cells such as histiocytes were ineffective. When the expression of PD-L1 was observed on the cell membrane, it was regarded as an effective functional image. In other words, it was ineffective when the cell membrane was 28-8 negative and cytoplasm was positive. Representative PD-L1 positive samples and negative samples are shown in Figure 1. We also performed a preliminary study using two other PD-L1 antibodies (SP142 and E1J2J) and compared results with staining with the PD-L1 28-8 antibody to determine the cutoff line for positivity or negativity.

\section{Comparison between TMA and whole sections}

PD-L1 expression was evaluated in whole sections from 23 cases that were randomly selected, irrespective of clinicopathological findings, to ascertain the potential consistency or discrepancy between TMA and whole section staining.

\section{Statistical analysis}

The correlation between PD-L1 expression and clinicopathological variables was statistically analysed using IBM SPSS Statistics 24 , and a $p$-value less than .05 was regarded as significant.

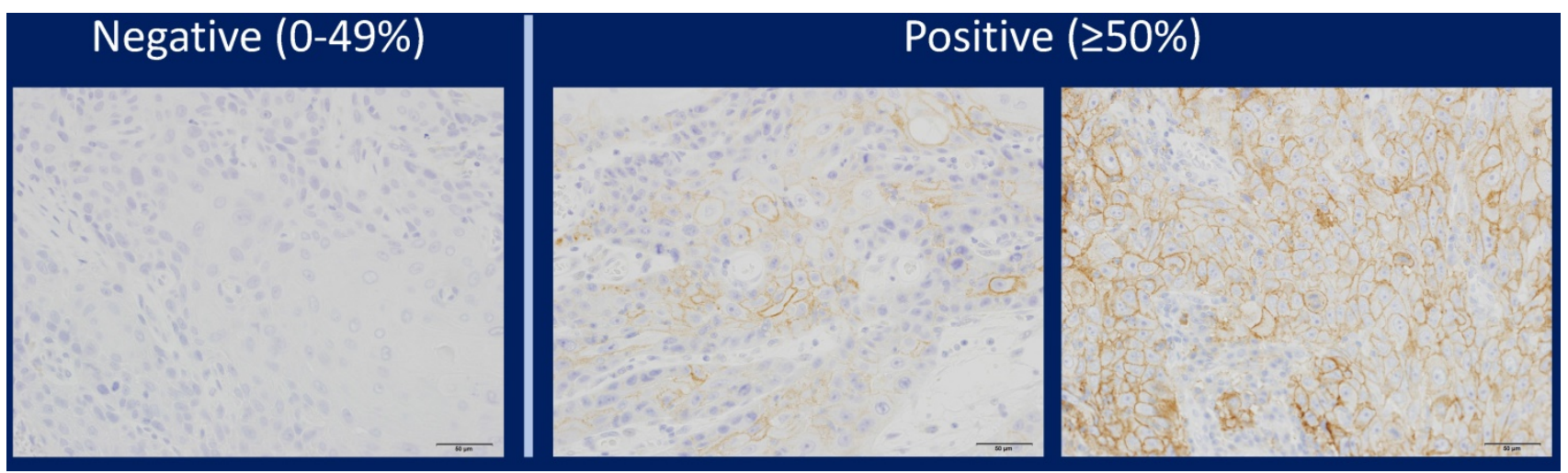

Figure 1. Representative images of immunohistochemical staining of PD-L1 in tongue SCC cases. PD-L1 expression was semi-quantitatively evaluated as negative (0-49\% positive staining) or positive (over 50\% positive staining). Positive PD-LI staining was observed in the cell membrane. 


\section{Results}

\section{Clinicopathological findings}

The 135 cases with tongue SCC were subclassified according to the clinicopathological variables, such as sex, age, tumour location (dorsal, marginal, ventral), volume, invasion depth, differentiation (well/moderately/poorly), TNM classification (UICC $7^{\text {th }}$ ), YK classification, vascular invasion, lymphatic invasion, neural invasion, lymph node metastasis (LNM) with/without extra-nodal extension, local recurrence, and prognosis (Table 1). We observed the following distribution: pT1, 41 cases (30\%); pT2, 56 cases (42\%); pT3, 20 cases $(15 \%)$; and pT4, 18 cases $(13 \%)$.

\section{PD-LI immunohistochemistry}

We performed immunohistochemical analysis for PD-L1 staining and classified the cases into positive and negative expression groups as described in Methods. Among cases in which the tumour infiltration depth was $3 \mathrm{~mm}$ or less, $23 \%(5 / 22)$ of cases showed PD-L1 positivity (Table 2). Among cases in which the tumour infiltration was deeper than 3 $\mathrm{mm}, 28 \%(32 / 113)$ showed PD-L1 positivity in the superficial area and 29\% (33/113) showed positivity in the deeper area. Figure 2 shows the distribution of PD-L1 expression in the superficial and deep parts in the same sample among cases in which the tumour infiltration was deeper than $3 \mathrm{~mm}(\mathrm{n}=113)$; most of the cases (90\%; 24 cases with positive staining in both sections and 75 cases with negative staining in both sections) showed consistent PD-L1 expression between the superficial part and the deep part in the same case. Only $10 \%$ of cases $(13 / 113)$ showed different staining between superficial and deep sections.

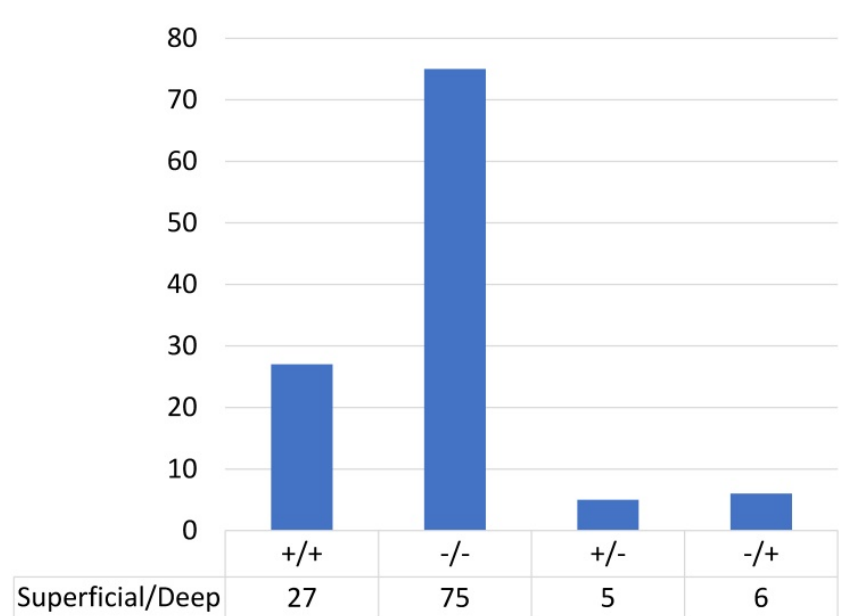

Figure 2. PD-L1 expression in superficial and deep parts within the same tongue SCC case $(n=113)$.
Table 1. Patient data and clinicopathological features

\begin{tabular}{|c|c|}
\hline Case & 135 \\
\hline \multicolumn{2}{|l|}{ Sex } \\
\hline male & 80 \\
\hline female & 55 \\
\hline \multicolumn{2}{|l|}{ Age } \\
\hline $20-29$ & 1 \\
\hline $30-39$ & 7 \\
\hline $40-49$ & 15 \\
\hline $50-59$ & 18 \\
\hline $60-69$ & 30 \\
\hline $70-79$ & 46 \\
\hline $80-89$ & 17 \\
\hline $90+$ & 1 \\
\hline \multicolumn{2}{|l|}{ Site } \\
\hline dorsal & 4 \\
\hline border & 119 \\
\hline ventral & 12 \\
\hline \multicolumn{2}{|l|}{ Volume } \\
\hline $0-9 \mathrm{~cm}^{3}$ & $89(69.0 \%)$ \\
\hline $10-19 \mathrm{~cm}^{3}$ & $17(13.2 \%)$ \\
\hline $20-29 \mathrm{~cm}^{3}$ & $8(6.2 \%)$ \\
\hline $30-39 \mathrm{~cm}^{3}$ & $7(5.4 \%)$ \\
\hline $40 \mathrm{~cm}^{3+}$ & $8(6.2 \%)$ \\
\hline \multicolumn{2}{|l|}{ Differentiation } \\
\hline well & $91(67.4 \%)$ \\
\hline moderately & $38(28.2 \%)$ \\
\hline poorly & $6(4.4 \%)$ \\
\hline \multicolumn{2}{|l|}{ pT } \\
\hline 1 & $41(30.4 \%)$ \\
\hline 2 & $56(41.5 \%)$ \\
\hline 3 & $20(14.8 \%)$ \\
\hline 4 & $18(13.3 \%)$ \\
\hline \multicolumn{2}{|l|}{ pN } \\
\hline 0 & $80(59.3 \%)$ \\
\hline 1 & $22(16.3 \%)$ \\
\hline 2 & $33(24.4 \%)$ \\
\hline \multicolumn{2}{|l|}{ YK } \\
\hline 1 & 0 \\
\hline 2 & $15(11.1 \%)$ \\
\hline 3 & $80(59.3 \%)$ \\
\hline 4 & $40(29.6 \%)$ \\
\hline \multicolumn{2}{|r|}{ 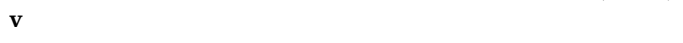 } \\
\hline- & 72 \\
\hline \multirow{2}{*}{\multicolumn{2}{|c|}{ ly }} \\
\hline & \\
\hline - & 117 \\
\hline+ & 18 \\
\hline \multicolumn{2}{|l|}{ neu } \\
\hline- & 91 \\
\hline+ & 44 \\
\hline \multicolumn{2}{|l|}{ ENE } \\
\hline - & 119 \\
\hline+ & 16 \\
\hline \multicolumn{2}{|l|}{ LR } \\
\hline - & 126 \\
\hline+ & 9 \\
\hline \multicolumn{2}{|l|}{ DM } \\
\hline- & 95 \\
\hline+ & 40 \\
\hline \multicolumn{2}{|l|}{ Prognosis } \\
\hline survival or unknown & 112 \\
\hline death & 23 \\
\hline
\end{tabular}

Abbreviations: pT: pathological assessment of the primary tumour; $\mathrm{pN}$ : pathological assessment of the regional lymph nodes; * $\mathrm{pT}$ and $\mathrm{pN}$ criteria follow TNM classification of Malignant Tumours 7th Edition, published by Union International Cancer Control; YK Yamamoto-Kohama classification; * the evaluating method of mode of invasion, used in General Rules for Clinical and Pathological Studies on Oral Cancer, the first edition; v: vessel invasion; ly: lymphatic invasion; neu: neural invasion; ENE: extranodal extension; LR: local recurrence; DM: distant metastasis 
Match case and mismatch case between PD-L1 result of whole section and TMA

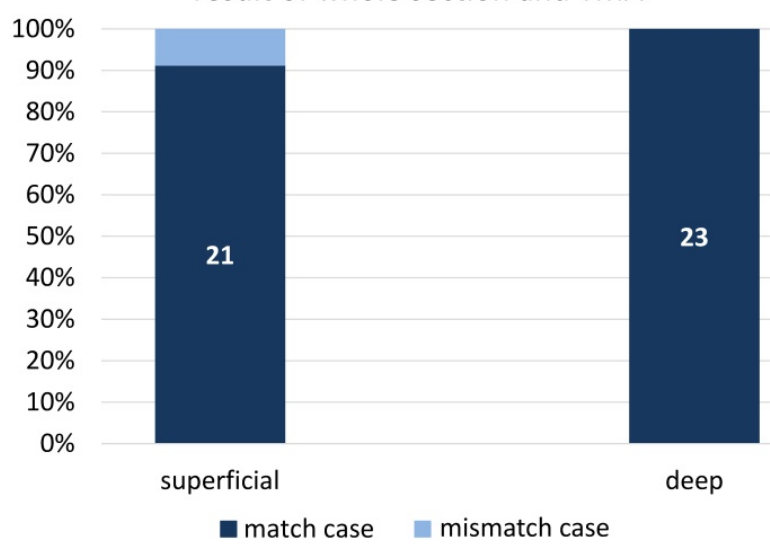

Figure 3. Comparison of PD-L1 expression in 23 cases that were randomly selected, irrespective of clinicopathological findings, to examine the consistency of PD-L1 staining between TMA and whole section staining.

We also evaluated PD-L1 in whole sections from 23 randomly selected cases to examine the consistency of PD-L1 staining between TMA and whole section staining. The coincidence rate of PD-L1 expression was 91\% (21/23) between the superficial part and whole section, and the rate was 100\% (23/23) between the deep part and whole section (Figure 3).

\section{Correlation of PD-L1 with clinicopathological findings}

The correlation between PD-L1 expression and clinicopathological findings by logistic regression analysis was significant for $\mathrm{pT}$ subclassification and LNM, but not for other variables (Table 3). There was a low positive correlation between pT1 and pT2 ( $\mathrm{r}=$ 0.256, $p<0.05)$, while there was a low negative correlation between pT2, pT3, and pT4 ( $\mathrm{r}=-0.243, p<$ 0.05 ) (Figure 4 ). We next performed analysis based on subgroups and tumour volume. In the pT1 subgroup, 33 out of 56 cases (59\%) were under $2,000 \mathrm{~mm}^{3}$; in the pT2 group, 55 out of 56 cases (98\%) were under 20,000 $\mathrm{mm}^{3}$; in the pT3 group, 16 out of 20 cases $(80 \%)$ were under $40,000 \mathrm{~mm}^{3}$; and there was a considerable wide range in tumour volume in the pT4 group (Figure 5). The PD-L1 positive rate markedly increased from $23 \%$ in tumours less than $2,000 \mathrm{~mm}^{3}$ (6/26 cases) to $79 \%$ in tumours 2,000 to $5000 \mathrm{~mm}^{3}$ (19/24 cases); in tumours with volumes over $5,000 \mathrm{~mm}^{3}$ the rate decreased to $33 \%(7 / 21$ cases). In the analysis of correlation between PD-L1 expression and LNM, the cases with LNM tended to show increased expression of PD-L1, and vice versa $(\mathrm{r}=0.240, p<0.05)$.

\section{Survival analysis based on PD-L1 expression}

We performed Kaplan Myer curve to examine the potential correlation between PD-L1 expression and survival rate, but no correlation was found (Figure 6).

Table 2. PD-LI expression ratio

\begin{tabular}{lllll}
\hline & & & depth $\geq 3 \mathbf{~ m m}$ & \\
\cline { 3 - 5 } & & depth $<3 \mathbf{~ m m}$ & superficial & deep \\
\hline PD-L1 & + & 5 & 32 & 33 \\
& - & 17 & 81 & 80 \\
& total & 22 & 113 & \\
\hline
\end{tabular}

Table 3. PD-L1 expression and clinicopathological findings

\begin{tabular}{|c|c|c|c|c|c|c|c|c|}
\hline \multirow{2}{*}{$\begin{array}{l}\text { Sex } \\
\text { PD-L1 }\end{array}$} & \multicolumn{2}{|c|}{ male } & \multicolumn{2}{|c|}{ female } & & & & \\
\hline & + & - & + & - & & & & \\
\hline & 19 & 61 & 19 & 36 & & & & \\
\hline & 80 & & 55 & & & & & \\
\hline \multirow[t]{4}{*}{ Site } & \multicolumn{2}{|c|}{ dorsal } & \multicolumn{2}{|c|}{ border } & \multicolumn{2}{|c|}{ ventral } & & \\
\hline & + & - & + & - & + & - & & \\
\hline & 1 & 3 & 34 & 85 & 3 & 9 & & \\
\hline & 4 & & 119 & & 12 & & & \\
\hline \multirow[t]{4}{*}{ Differentiation } & \multicolumn{2}{|c|}{ well } & \multicolumn{2}{|c|}{ moderately } & \multicolumn{2}{|c|}{ poorly } & & \\
\hline & + & - & + & - & + & - & & \\
\hline & 22 & 69 & 13 & 25 & 3 & 3 & & \\
\hline & 91 & & 38 & & 6 & & & \\
\hline \multirow[t]{4}{*}{ pT } & 1 & & 2 & & 3 & & \multicolumn{2}{|l|}{4} \\
\hline & + & - & + & - & + & - & + & - \\
\hline & 7 & 34 & 23 & 33 & 6 & 14 & 2 & 16 \\
\hline & 41 & & 56 & & 20 & & 18 & \\
\hline \multirow[t]{4}{*}{$\mathrm{pN}$} & \multicolumn{2}{|l|}{0} & \multicolumn{2}{|l|}{1} & \multicolumn{2}{|l|}{2} & & \\
\hline & + & - & + & - & + & - & & \\
\hline & 17 & 63 & 8 & 14 & 12 & 21 & & \\
\hline & 80 & & 22 & & 33 & & & \\
\hline \multirow[t]{4}{*}{ YK classification } & \multicolumn{2}{|l|}{2} & 3 & & 4 & & & \\
\hline & + & - & + & - & + & - & & \\
\hline & 2 & 13 & 23 & 57 & 13 & 27 & & \\
\hline & 15 & & 80 & & 40 & & & \\
\hline V & + & & - & & & & & \\
\hline & + & - & + & - & & & & \\
\hline & 20 & 43 & 18 & 54 & & & & \\
\hline & 63 & & 72 & & & & & \\
\hline Ly & + & & - & & & & & \\
\hline & + & - & + & - & & & & \\
\hline & 3 & 15 & 35 & 82 & & & & \\
\hline & 18 & & 117 & & & & & \\
\hline Neu & + & & - & & & & & \\
\hline & + & - & + & - & & & & \\
\hline & 14 & 30 & 24 & 67 & & & & \\
\hline & 44 & & 91 & & & & & \\
\hline ENE & + & & - & & & & & \\
\hline & + & - & + & - & & & & \\
\hline & 4 & 13 & 34 & 84 & & & & \\
\hline & 17 & & 118 & & & & & \\
\hline LR & + & & - & & & & & \\
\hline & + & - & + & - & & & & \\
\hline & 2 & 7 & 36 & 90 & & & & \\
\hline & 9 & & 126 & & & & & \\
\hline DM & + & & - & & & & & \\
\hline & + & - & + & - & & & & \\
\hline & 10 & 30 & 28 & 67 & & & & \\
\hline & 40 & & 95 & & & & & \\
\hline Prognosis & $\begin{array}{l}\text { surv } \\
\text { unk }\end{array}$ & $\begin{array}{l}\text { jal or } \\
\text { own }\end{array}$ & dea & & & & & \\
\hline & + & - & + & - & & & & \\
\hline & 32 & 80 & 5 & 18 & & & & \\
\hline & 112 & & 23 & & & & & \\
\hline
\end{tabular}




\section{Discussion}

Recently, immunotherapy that targets the PD-L1/PD-1 pathway is being applied to various cancers that are recurrent or resistant to typical chemotherapy.[17, 18] However, whether PD-L1 expression is related to clinical outcome has not been clear.[19] Some reports mention a positive correlation between prognosis and immunohistochemical PD-L1 expression,[8-11] while others report a negative correlation.[4-7] In head and neck cancer, especially SCC, similar conflicting findings have been published.[12, 13] PD-L1-targeted immunotherapy has also been applied to recurrent or refractory head and neck cancer, although the overall survival of head and neck cancer patients is favourable, in part due to a preventive cervical dissection.[20]

Immunohistochemical staining for routine practice or a cohort study is usually used as a surrogate procedure, but some challenges remain in these procedures, such as differences in staining depending on the antibody used [21] and staining heterogeneity even in the same section. Immunohistochemistry using TMA is a helpful strategy to address many cases at once and to determine the correlation between PD-L1 expression and the clinical outcome.[22] In this study, we attempted to examine the PD-L1 expression using three anti-PD-L1 antibodies (data not shown), but the results showed no significant differences and thus we chose to present the data analysed using the $28-8$ antibody as a representative antibody. The heterogeneity of PD-L1 expression is challenge during immunohistochemical evaluation, in particular when using TMA instead of a representative whole section.[23, 24] Here we examined 23 randomly selected cases to compare staining approaches. There was a minor difference (coincidence rate $90 \%$ ) in the PD-L1 staining results between the superficial part of the TMA and the whole section, and PD-L1 staining in the deep part of the TMA was consistent with the whole section. These results suggest that even the examination of PD-L1 expression based on biopsy specimens, which are usually obtained from the superficial part of tumour, may be the same as the surgically resected whole tumour.

In the analysis of correlation between PD-L1 expression and variable clinicopathological factors, PD-L1 expression was found to show a positive correlation between pT1 and pT2 but a negative correlation among pT2, pT3 and pT4. In the UICC $7^{\text {th }}$ edition, the pT classification is mainly based on tumour volume. The pT1 cases were predominantly under 2,000 $\mathrm{mm}^{3}$, the pT2 cases were under 20,000 $\mathrm{mm}^{3}$, and pT3 cases were under 40,000 $\mathrm{mm}^{3}$.
However, there was a considerable variability in the tumour volume in pT4 cases. As a result, as the tumour volume increased from 2,000 to $5,000 \mathrm{~mm}^{3}$, the PD-L1 positive rate increased with the highest rate in pT2 cases, but decreased from pT2 to pT4. This suggests that PD-L1 tends to be most strongly expressed at an early stage in tongue SCC, which may be linked to the theory that PD-L1 is essential for local growth as a relatively small size. This suggests that PD-L1 is not expressed continuously during the overall progression of tongue SCC. In colon cancer, there is also a report that the expression of PD-L1 decreases as the pT classification increases in this way. [25]

In this study, LNM-positive cases tended to show higher PD-L1 expression rates compared to negative cases. The presence or absence of lymph node metastasis is generally thought to be correlated with prognosis, but in this study no significant correlation was observed between PD-L1 expression and overall survival time and progression-free survival.

\begin{tabular}{|c|c|c|c|c|c|}
\hline & \multicolumn{4}{|c|}{ pT } \\
\hline & & 1 & 2 & 3 & 4 \\
\hline \multirow{2}{*}{ PD-L1 } & + & 7 & 23 & 6 & 2 \\
\hline & - & 34 & 33 & 14 & 16 \\
\hline
\end{tabular}
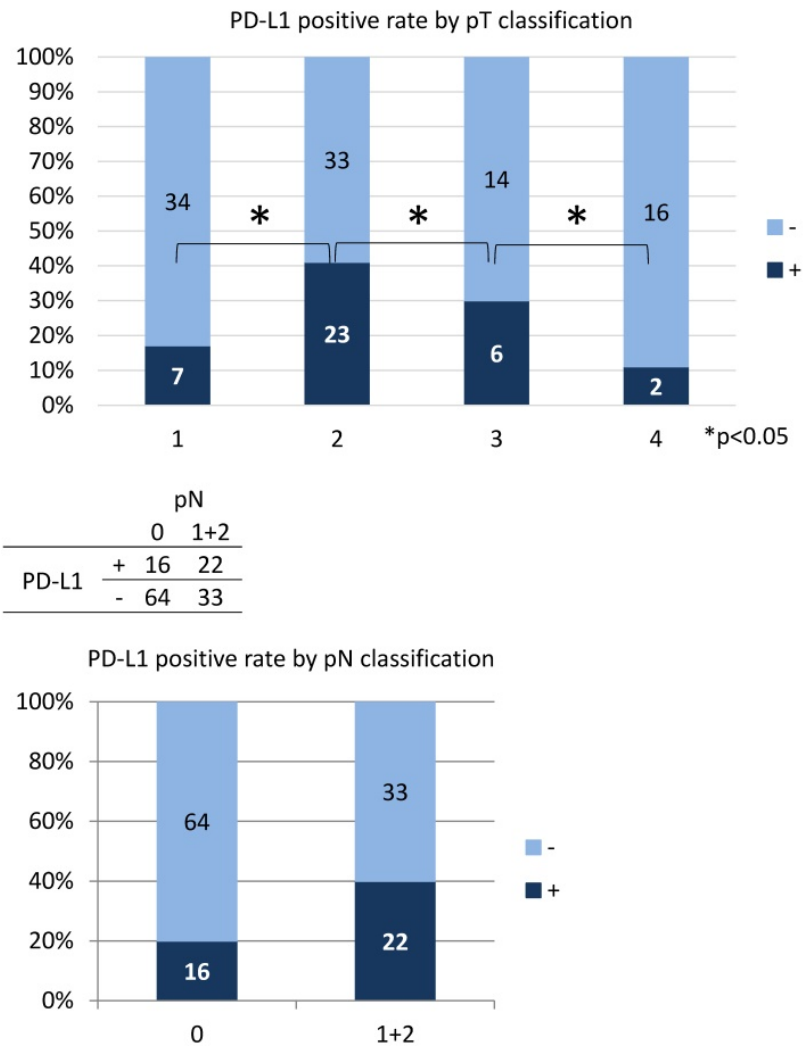

Figure 4. The results of the multiple logistic regression analysis by the variable increase method based on the likelihood ratio are as shown in the table. The model chi-square test result was significant at $p<0.05$. The result of Hosmer and Lemeshow Test was $p=1.000$, and the discriminant predictive value was $73.3 \%$. 


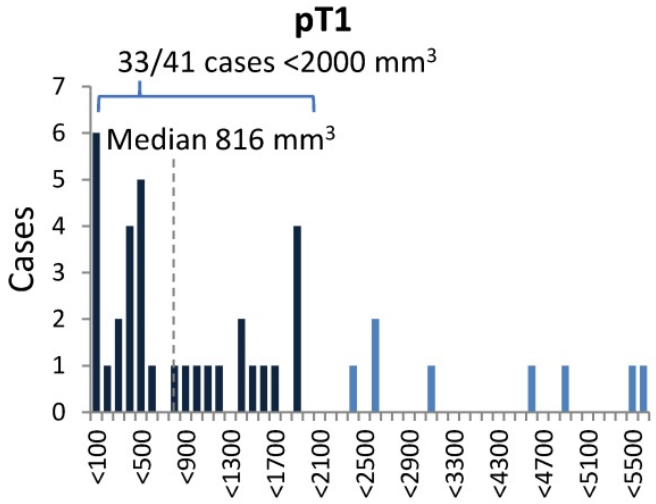

Tumor volume $\left(\mathrm{mm}^{3}\right)$

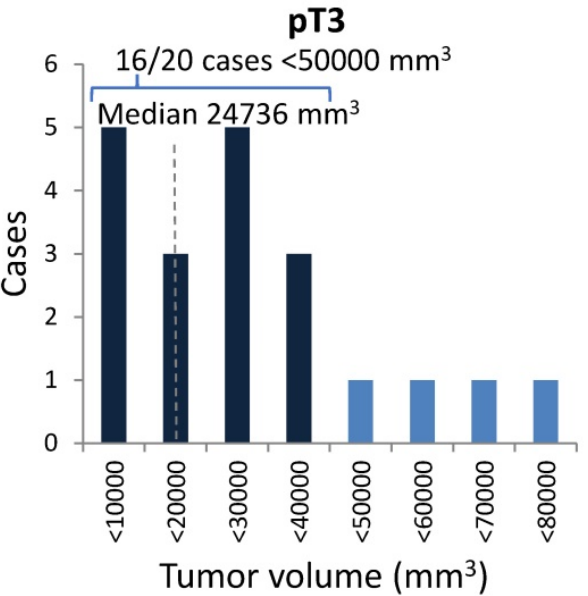

pT2

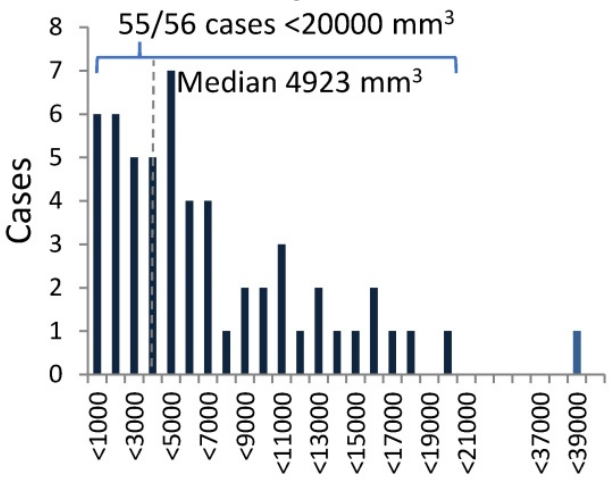

Tumor volume $\left(\mathrm{mm}^{3}\right)$

pT4

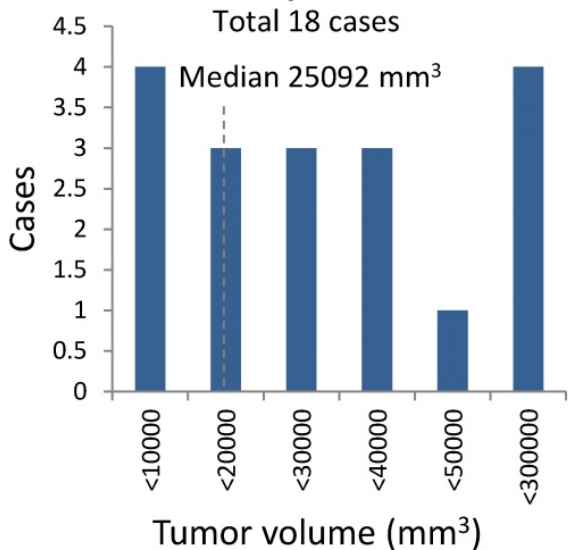

PD-L1 Positive rate

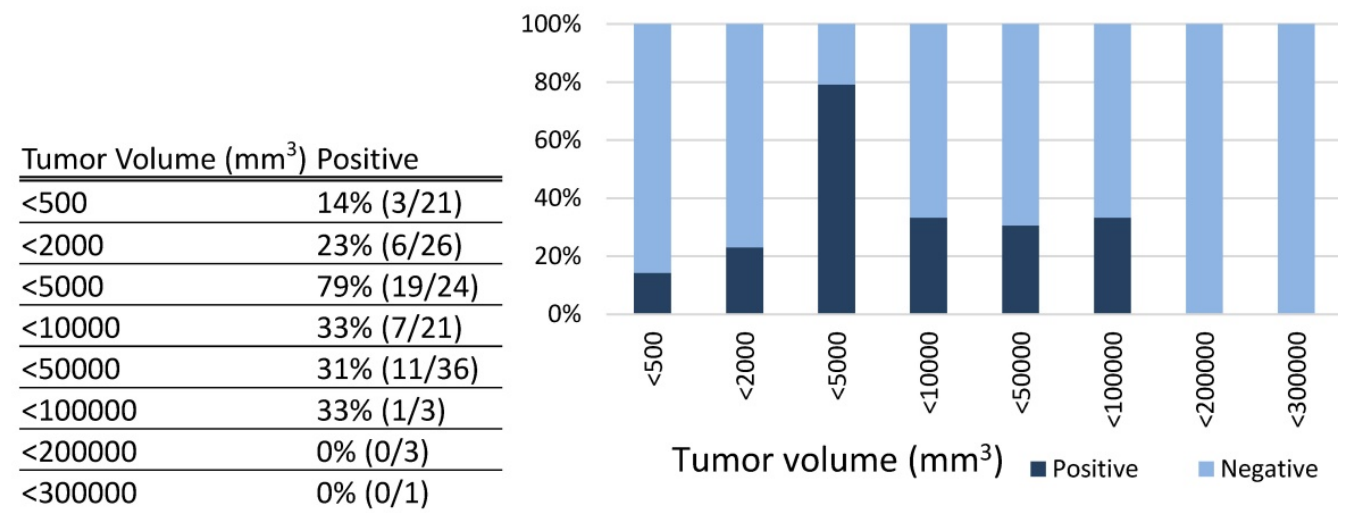

Figure 5. In the analysis based on subclassification of the tumour volume, 33 out of 56 cases (59\%) were under $2,000 \mathrm{~mm}^{3}$ in pT1; 55 out of 56 cases ( $98 \%$ ) were less than $20,000 \mathrm{~mm}^{3}$ in PT2; 16 out of 20 cases $\left(80 \%\right.$ ) were less than $40,000 \mathrm{~mm}^{3}$ in PT3; there was a considerable variability in the tumour volume in PT4. According to an increase of the tumour volume from less than 2,000 to more than 2,000 to $5000 \mathrm{~mm}^{3}$, the PD-LI positive rate increased markedly from $23 \%$ to $79 \%$, while the rate decreased to $33 \%$ with the volume surpassing $5,000 \mathrm{~mm}^{3}$.

Expression of PD-L1, lymph node metastasis, and prognosis are not simply linked, but mechanisms need to be examined more carefully. Some part of the advanced tongue SCC tumour may be effectively targeted by immunotherapy targeting PD-L1/PD-1. But, as for the therapy, in the determination of its introduction and prediction of its effect, the usefulness of immunohistochemical evaluation of
PD-L1 remains to be clarified. Not limited to immunohistochemical application of only PD-L1, some co-factor of PD-1 may be needed to be investigated to raise the reliability of PD-L1.[26] Further analysis of RNA expression in association with the immunohistochemical expression is now ongoing.[27] Future studies should also analyse PD-L1-related T-cells in future studies.[28, 29] 


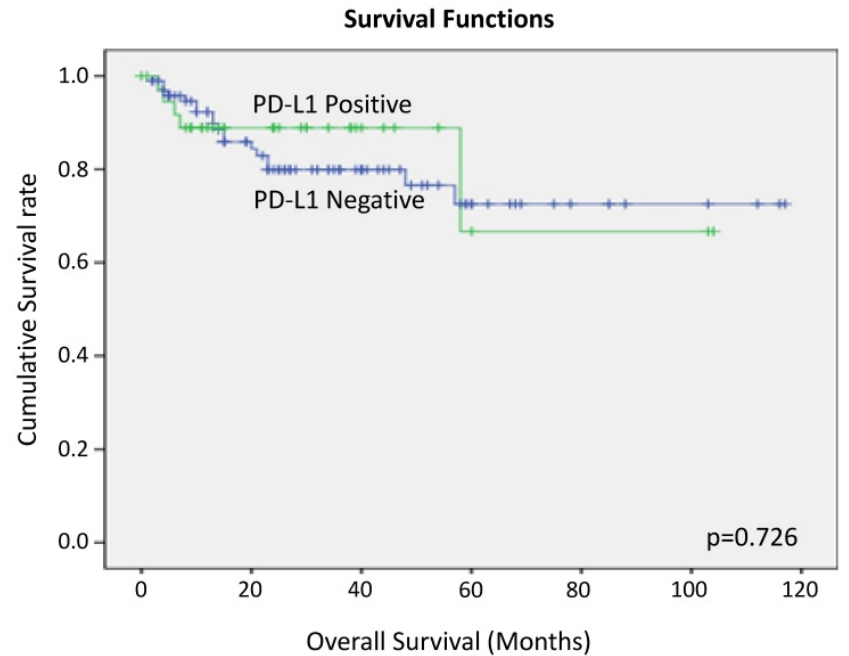

Figure 6. Overall survival of tongue SCC cases according to PD-L1 expression by Kaplan-Meier analysis.

PD-L1 expression in tongue SCC may be of significance as an early event of tumour growth, and therefore immunotherapy targeting PD-L1/PD-1 may be effective for the early stage tumour, rather than for advanced or recurrent cases. This observation may help generate a new therapeutic strategy for tongue SCC patients.

\section{Acknowledgements}

We thank Edanz Group (www.edanzediting. $\mathrm{com} / \mathrm{ac}$ ) for editing a draft of this manuscript.

\section{Funding}

This study was supported by: Hidaka Research Projects in Saitama Medical University International Medical Center (grant numbers: 28-D-1-15).

Grants-in-Aid from the Ministry of Education, Science, Sports and Culture of Japan (Research Project Numbers: 16K11441, 18K09789).

\section{Competing Interests}

The authors have declared that no competing interest exists.

\section{References}

1. Ichikawa M, Chen L. Role of B7-H1 and B7-H4 molecules in down-regulating effector phase of T-cell immunity: novel cancer escaping mechanisms. Front Biosci. 2005; 10: 2856-60.

2. Taube JM, Anders RA, Young GD, Xu H, Sharma R, McMiller TL, et al. Colocalization of inflammatory response with B7-h1 expression in human melanocytic lesions supports an adaptive resistance mechanism of immune escape. Science translational medicine. 2012; 4: 127ra37.

3. Kythreotou A, Siddique A, Mauri FA, Bower M, Pinato DJ. PD-L1. J Clin Pathol. 2018; 71: 189-94.

4. Chen $\mathrm{YB}, \mathrm{Mu} \mathrm{CY}$, Huang JA. Clinical significance of programmed death-1 ligand-1 expression in patients with non-small cell lung cancer: a 5-year-follow-up study. Tumori. 2012; 98: 751-5.

5. Mu CY, Huang JA, Chen Y, Chen C, Zhang XG. High expression of PD-L1 in lung cancer may contribute to poor prognosis and tumor cells immune escape through suppressing tumor infiltrating dendritic cells maturation. Med Oncol. 2011; 28: 682-8.
6. Azuma K, Ota K, Kawahara A, Hattori S, Iwama E, Harada T, et al. Association of PD-L1 overexpression with activating EGFR mutations in surgically resected nonsmall-cell lung cancer. Ann Oncol. 2014; 25: 1935-40.

7. Zhang Y, Wang L, Li Y, Pan Y, Wang R, Hu H, et al. Protein expression of programmed death 1 ligand 1 and ligand 2 independently predict poor prognosis in surgically resected lung adenocarcinoma. OncoTargets and therapy. 2014; 7: 567-73.

8. Yang CY, Lin MW, Chang YL, Wu CT, Yang PC. Programmed cell death-ligand 1 expression in surgically resected stage I pulmonary adenocarcinoma and its correlation with driver mutations and clinical outcomes. Eur J Cancer. 2014; 50: 1361-9.

9. Velcheti V, Schalper KA, Carvajal DE, Anagnostou VK, Syrigos KN, Sznol M, et al. Programmed death ligand-1 expression in non-small cell lung cancer. Lab Invest. 2014; 94: 107-16.

10. Droeser RA, Hirt C, Viehl CT, Frey DM, Nebiker C, Huber X, et al. Clinical impact of programmed cell death ligand 1 expression in colorectal cancer. Eur J Cancer. 2013; 49: 2233-42.

11. Vassilakopoulou M, Avgeris M, Velcheti V, Kotoula V, Rampias T, Chatzopoulos K, et al. Evaluation of PD-L1 Expression and Associated Tumor-Infiltrating Lymphocytes in Laryngeal Squamous Cell Carcinoma. Clinical cancer research : an official journal of the American Association for Cancer Research. 2016; 22: 704-13.

12. Straub M, Drecoll E, Pfarr N, Weichert W, Langer R, Hapfelmeier A, et al. CD274/PD-L1 gene amplification and PD-L1 protein expression are common events in squamous cell carcinoma of the oral cavity. Oncotarget. 2016; 7: 12024-34.

13. Satgunaseelan L, Gupta R, Madore J, Chia N, Lum T, Palme CE, et al. Programmed cell death-ligand 1 expression in oral squamous cell carcinoma is associated with an inflammatory phenotype. Pathology. 2016; 48: 574-80.

14. Scheel AH, Dietel M, Heukamp LC, Johrens K, Kirchner T, Reu S, et al. Harmonized PD-L1 immunohistochemistry for pulmonary squamous-cell and adenocarcinomas. Modern pathology : an official journal of the United States and Canadian Academy of Pathology, Inc. 2016; 29: 1165-72.

15. Daud AI, Wolchok JD, Robert C, Hwu WJ, Weber JS, Ribas A, et al. Programmed Death-Ligand 1 Expression and Response to the Anti-Programmed Death 1 Antibody Pembrolizumab in Melanoma. Journal of clinical oncology : official journal of the American Society of Clinical Oncology. 2016; 34: 4102-9.

16. Horinouchi H. KEYNOTE-010: flash of a supernova (immune-checkpoint inhibitors) in second-line non-small cell lung cancer. J Thorac Dis. 2017; 9: 4187-90.

17. Balar AV, Castellano D, O'Donnell PH, Grivas P, Vuky J, Powles T, et al. First-line pembrolizumab in cisplatin-ineligible patients with locally advanced and unresectable or metastatic urothelial cancer (KEYNOTE-052): a multicentre, single-arm, phase 2 study. Lancet Oncol. 2017; 18: 1483-92.

18. Yeh J, Marrone KA, Forde PM. Neoadjuvant and consolidation immuno-oncology therapy in stage III non-small cell lung cancer. J Thorac Dis. 2018; 10: S451-s9.

19. Wang X, Teng F, Kong L, Yu J. PD-L1 expression in human cancers and its association with clinical outcomes. OncoTargets and therapy. 2016; 9: 5023-39.

20. Larkins E, Blumenthal GM, Yuan W, He K, Sridhara R, Subramaniam S, et al. FDA Approval Summary: Pembrolizumab for the Treatment of Recurrent or Metastatic Head and Neck Squamous Cell Carcinoma with Disease Progression on or After Platinum-Containing Chemotherapy. Oncologist. 2017; 22: 873-8.

21. Sun WY, Lee YK, Koo JS. Expression of PD-L1 in triple-negative breast cancer based on different immunohistochemical antibodies. J Transl Med. 2016; 14: 173

22. Liang $X$, Sun J, Wu H, Luo $Y$, Wang L, Lu J, et al. PD-L1 in pancreatic ductal adenocarcinoma: a retrospective analysis of 373 Chinese patients using an in vitro diagnostic assay. Diagn Pathol. 2018; 13: 5

23. Botti G, Scognamiglio G, Cantile M. PD-L1 Immunohistochemical Detection in Tumor Cells and Tumor Microenvironment: Main Considerations on the Use of Tissue Micro Arrays. Int J Mol Sci. 2016; 17.

24. Munari E, Zamboni G, Marconi M, Sommaggio M, Brunelli M, Martignoni G, et al. PD-L1 expression heterogeneity in non-small cell lung cancer: evaluation of small biopsies reliability. Oncotarget. 2017; 8: 90123-31

25. Yagi L, Lei L, Weixing D, Guoxiang C, Ye X, Xinxiang L, et al. Prognostic impact of programed cell death-1 (PD-1) and PD-ligand 1 (PD-L1) expression in cancer cells and tumour infiltrating lymphocytes in colorectal cancer. Mol Cancer. 2016; 15:55

26. Joneja U, Vranic S, Swensen J, Feldman R, Chen W, Kimbrough J, et al. Comprehensive profiling of metaplastic breast carcinomas reveals 
frequent overexpression of programmed death-ligand 1. J Clin Pathol. 2017; 70: 255-9.

27. Weber M, Wehrhan F, Baran C, Agaimy A, Buttner-Herold M, Preidl R, et al. PD-L1 expression in tumor tissue and peripheral blood of patients with oral squamous cell carcinoma. Oncotarget. 2017; 8: 112584-97.

28. Concha-Benavente F, Srivastava RM, Trivedi S, Lei Y, Chandran U, Seethala RR, et al. Identification of the Cell-Intrinsic and -Extrinsic Pathways Downstream of EGFR and IFNgamma That Induce PD-L1 Expression in Head and Neck Cancer. Cancer Res. 2016; 76: 1031-43.

29. Lipson EJ, Vincent JG, Loyo M, Kagohara LT, Luber BS, Wang H, et al. PD-L1 expression in the Merkel cell carcinoma microenvironment: association with inflammation, Merkel cell polyomavirus and overall survival. Cancer immunology research. 2013; 1: 54-63. 